\title{
Uma geometria de caso para o português brasileiro
}

Danniel Carvalho ${ }^{1}$

\section{Resumo}

Este trabalho discute a realização de uma mesma forma pronominal em diferentes contextos sintáticos. De forma comparativa, desconstrói-se a ideia de caso com uma categoria determinante na distribuição pronominal. Demonstra-se como uma teoria tradicional de caso é insuficiente para lidar com sincretismo. Uma decomposição das categorias de caso é sugerida como uma solução ótima para a configuração de caso, levando em conta principalmente evidências de línguas como o inglês e o português brasileiro, que apresentam diferenças casuais apenas em seus pronomes pessoais. Caso, portanto, é tratado a partir de uma hierarquia de traços, nos moldes de Harley \& Ritter (2002). Assim, as categorias de caso para o português brasileiro obedecem à geometria [C[OBL[GEN]]]. Um mecanismo de valoração destes traços é proposto e os diferentes outputs pronominais são o resultado deste mecanismo, o que explica o atual quadro pronominal no português.

Palavras-chave: Teoria do Caso. Sincretismo. Pronomes. Português brasileiro

${ }^{1}$ UFBA - Universidade Federal da Bahia; Instituto de Letras; Salvador; Bahia; Brasil; dannielcarvalho@ufba.br 


\section{Introdução}

Morfologicamente, a maioria das pessoas pronominais parecem não depender de outro mecanismo gramatical, tal como caso, além dos traços pessoa, número e gênero (traços- $\varphi$ ), para sua definição formal, uma vez que suas formas morfológicas são restritas apenas, na maioria dos casos, à “nominativa". Entretanto, a especificação de traços $\varphi$ não é suficiente para explicar como eu pode aparecer em todas as posições argumentais, em (1), substituindo as outras formas, que denomino casuais, de primeira pessoa (me, mim, meu, minha...) vistas em (2).

(1) a. Minha mãe mandou eu pra escola.

b. Maria deu um presente pra $e u$.

c. Ela nunca falou com eu.

d. Ela puxou na cabeça deu.

(2) a. Minha mãe me mandou pra escola.

b. Maria deu um presente pra mim.

c. Ela nunca falou comigo.

d. Ela puxou na minha cabeça.

Aparentemente, os pronomes de primeira pessoa do singular levam em conta mais do que o conjunto de traços de concordância $(\varphi)$ para determinar sua forma e distribuição. Assumirei, portanto, que eles também levam em conta caso e, tomando (1) e (2) acima, além de outros exemplos que serão apresentados adiante como evidência, que traços de caso participam do processo de concordância dos DPs. Isto também se justifica, pois estas alternâncias apresentam restrições de cunho estrutural, o que as condicionam também à sintaxe. Assim, proporei uma geometria de traços de caso, baseada em subespecificação de traços (HARLEY \& RITTER, 2002). Ainda, argumentarei em favor de uma dissolução da noção de "caso estrutural" como um universal, reiterando o que já mostram alguns estudos (BOECKX, 2008, 2014; McFADDEN, 2002, 2004, 2007; SIGURĐSSON, 2000, 2003). 


\section{Decompondo caso}

Tradicionalmente, caso pode ser definido como uma relação, semanticamente associada ou não, entre um DP e seu contexto sintático. Caso inerente (ou profundo) seria semanticamente associado, enquanto caso estrutural, não. Ambos os casos podem ser (mas não necessariamente são) refletidos por um caso morfológico. Muitas línguas marcam a função gramatical de seus nominais com afixos específicos que, juntos, determinam seu "sistema de casos". Línguas com um sistema de casos "rico" podem dispor de uma grande variedade de casos (o finlandês possui mais de 12 casos, enquanto o alemão possui 5, por exemplo). Assim, geralmente, os chamados casos nominativo, acusativo e dativo marcariam numa oração, respectivamente, o DP na posição sujeito, objeto direto e objeto indireto. No alemão, língua com sistema casual morfologicamente expresso, o artigo (masculino, neste exemplo) marca a declinação de caso para cada elemento nominal: der para o nominativo, den para o acusativo, e dem para o dativo:
(3) Der Mann
gab den Hund
dem Sohn
O homem.nom
deu o
cachorro.ac
ao filho.dat

Algumas línguas, como o inglês, entretanto, não dispõem mais de um sistema casual morfologicamente visível em seus nomes, mas ainda mostrariam um resíduo de tal sistema casual em seu sistema pronominal.

$$
\begin{aligned}
& \text { (4) a. He likes her } \\
& \text { Ele(nom) gosta ela(ac) } \\
& \text { "Ele gosta dela" } \\
& \text { b. She likes him } \\
& \text { Ela(nom) gosta ele(ac) } \\
& \text { "Ela gosta dele" }
\end{aligned}
$$

Em (4), as diferentes formas pronominais representam diferentes casos: he e she são as formas pronominais para o nominativo da terceira pessoa do singular masculino e feminino, respectivamente, enquanto him e her representam suas formas acusativas.

Uma teoria de caso, portanto, deve dar conta da distribuição e forma de um DP realizado. A proposta de Rouveret e Vergnaud (1980), na qual todo NP deve receber um caso para ser legível em LF e PF, o chamado Filtro de Caso, foi adotada por Chomsky e 
incluída no aparato teórico de Regência e Ligação (CHOMSKY, 1981) como um módulo da gramática. Entretanto, a noção de caso abstrato como um fator determinante para a distribuição dos DPs vem tendo um enfraquecimento no decorrer do desenvolvimento da teoria da gramática. Diversos estudos feitos sobre inúmeras línguas mostram uma extensiva gama de contra-evidências a esta "universalidade" de caso (como no islandês [McFADDEN, 2002; SIGURĐSSON, 2003], japonês e hindu [MCFADDEN, op. cit.], e PB [ALBUQUERQUE, 2006], entre muitas outras). Isso pode ser ilustrado com o islandês, onde a mesma preposição (i) atribui tanto o caso acusativo (5)a. quanto o dativo (5)b.

\section{(5) a. Hún hljóp í bæinn.}

Ela correu em centro.o.ac

"Ela correu para o centro"

b. Hún hljóp (um) í bænum.

Ela correu (em volta) em centro.o.dat

"Ela correu ao redor do centro"

(SIGURĐSSON, 2003, p. 234)

Nichols (1992), em um estudo tipológico, verifica que cerca de 45\% das línguas do mundo não possuem caso morfológico (chinês e línguas asiáticas na sua maioria), 50\% seriam línguas casualmente marcadas (alemão e algumas línguas germânicas e escandinavas), e o restante, cerca de 5\%, seriam línguas de marcação casual pobre (case-poor languages). Esse último tipo englobaria línguas como o inglês, o francês, o espanhol, o português, entre outras, que revelam apenas uma "herança" do caso morfológico no sistema pronominal. A partir dessas informações, a presença/ausência de caso pode ser formalizada em três abordagens (SIGURĐSSON, 2003, p. 224-225):

(i) Abordagem Morfológica: A noção de caso é puramente morfológica, portanto DPs lexicais em inglês e todos os DPs em chinês não possuem caso, enquanto os pronomes do inglês possuem caso. 
(ii) Abordagem de Língua Específica: Uma língua ou tem ou não tem um sistema casual. Assim, todo DP do inglês recebe caso - visivelmente ou não - enquanto caso é ausente no chinês.

(iii) Abordagem Universal: DPs universalmente recebem caso, pelo menos abstratamente.

Essas abordagens não seriam mutuamente excludentes: a Abordagem Universal prediz um caso abstrato como um mecanismo universal e um potencial expediente em línguas marcadas com caso morfológico. Por esta razão, poderia se supor que caso morfológico seria uma implementação de PF, enquanto caso abstrato, algo inerente à sintaxe propriamente dita, não havendo necessariamente reciprocidade entre caso abstrato e caso morfológico. A Proposta Universal, portanto, é interpretada como a definição do Filtro de caso (ROUVERET \&VERGNAUD, 1980; CHOMSKY, 1981): todo NP deve ter caso para ser visível em LF e PF. Adotando-se também o Princípio da Uniformidade (CHOMSKY, 1998, p. 2), que afirma que as línguas são sintaticamente uniformes e a variação entre elas é devida ao componente fonológico (PF), Sigurðsson (2003, p. 225) sugere que, uma vez que a concepção de caso abstrato é um fenômeno universal, cujo lugar é a sintaxe estreita, somos levados a conceber caso morfológico como um expoente de PF. Isso reforça o fato de que, em algumas línguas, um único caso abstrato pode ser expresso morfologicamente de diferentes formas, como visto em islandês com o dativo ${ }^{2}$.

(6) a. Sujeito Dativo

Henni líkaði pessi hugmynd.

Ela.dat gostou esta idéia.nom

"Ela gostou desta idéia"

b. Objet Indireto Dativo ${ }^{3}$

Hún gaf mér bókina.

\footnotetext{
2 Extraído de Sigurðsson (2003, p. 231-233).

$3 \mathrm{O}$ caso atribuído ao objeto indireto em islandês é o Dativo, o mesmo do denominado objeto preposicionado. Geralmente, objetos indiretos em islandês desempenham um papel Benefactivo, enquanto objetos preposicionados desempenham o de Alvo. Isto, entretanto, é irrelevante para a discussão que pretendo desenvolver.
} 
Ela deu me.dat livro.o.ac

"Ela me deu o livro"

c. Objeto Direto Dativo

Við hjálpuðum henni.

Nós ajudamos.pass ela.dat

d. Benefactivo Livre Dativo (Dativo Ético)

Ég lagaði mér kaffi.

Eu fiz me.dat café

"Eu me fiz café"

e. Dativo Preposicionado

Hún fór að húsinu.

Ela foi na.direção.de.casa.a.dat

"Ela foi para casa"

\section{f. Objeto Adjetival Dativo}

Hann er líkur henni.

Ele é similar ela.dat

"Ele parece com ela"

Semelhantemente em PB quase não há restrição quanto ao caso representado pelos pronomes em sua distribuição, como ilustrado em (7), exceto com a primeira pessoa do singular em certos contextos. 
(7) a. A menina viu ele(ac).

b. A menina entregou o pacote pra/a ele(dat). ${ }^{4}$

c. O guarda parou nós $(\mathrm{ac})$.

d. O vendedor demonstrou o produto para/a nós(dat).

Adotando esta ideia central, assumiremos que caso é, na verdade, apenas uma "leitura" de diversos fatos sintáticos, tais como o resultado de concordância do DP.

Algumas distinções tradicionalmente atribuídas a caso parecem de fato arbitrárias. Em (8) abaixo, por exemplo, a gente e vocês podem aparecer em qualquer posição argumental em uma sentença:

(8) a. Vocês viram a gente ontem.

b. A gente viu vocês ontem.

c. Vocês deram isso para a gente.

d. A gente deu isso para vocês.

e. Vocês gostaram do cabelo da gente.

f. A gente gostou do cabelo de vocês.

Tanto vocês quanto a gente têm a mesma distribuição Casual sem que haja mudança em suas formas. Em outras palavras, há uma única forma para todas as posições Casuais em que estes pronomes ocorrem. Isto acontece também com os pronomes no singular, como pode ser observado em (9).

(9) a. Elas viram você/tu ontem.

b. Você/tu viu elas ontem?

c. Elas deram isso pra você/tu.

\footnotetext{
${ }^{4}$ Há uma tendência ao uso de para em vez de $a$, em PB. Esta variação, entretanto, não é relevante para os
} objetivos do presente estudo. 
Você é uma forma pronominal para a segunda pessoa do singular em PB (ao lado de tu), e é esperado que tenha uma distribuição mais ampla, pois historicamente não possui nenhuma outra forma Casual mais específica. Mesmo $t u$, que apresenta historicamente essas formas Casuais mais específicas, não encontra restrições na sua distribuição.

Com a primeira pessoa do singular é semelhante: (10) abaixo mostra que esta pessoa pode apresentar uma única forma (nominativa) em todas as posições argumentais em $\mathrm{PB}$, mesmo sendo a única que ainda apresenta formas específicas em alguns contextos para os diferentes casos.

(10) a. Minha mãe mandou eu pra escola.

b. Maria deu um presente pra $e \boldsymbol{u}$.

c. Ela nunca falou com eu.

d. Ela puxou na cabeça deu.

Os requerimentos casuais parecem não corresponder à univocidade do Filtro de Caso e, em vez disso, a forma e a função do DP pronominal parecem derivar das operações sintáticas nas quais seus traços, inclusive os de caso, serão valorados. Um mecanismo assim pode ser alcançado através de uma revisão da categoria caso: os tradicionais casos abstratos (nominativo, acusativo, dativo, etc.) obedeceriam uma composição de elementos mais atômicos e a combinação desses elementos é que vai determinar, em PF, a função do DP pronominal e sua consequente forma final ${ }^{5}$. Tal proposta parece mais viável visto que não necessita lançar mão previamente da morfologia do pronome, o que elimina o problema inicial criado pela vinculação da função do pronome a sua forma. Além disso, uma teoria como esta é empiricamente mais econômica, pois a combinação de um número limitado de traços é suficiente para definir e explicar, a partir da estrutura interna do DP, fenômenos como o sincretismo, encontrado, por exemplo, com a primeira pessoa do singular em $\mathrm{PB}$, sem se apelar a fatores externos ao DP. Isso também não é uma novidade teórica. Alguns estudos já trazem propostas semelhantes (McFADDEN, 2007), as quais serão discutidas a seguir e servirão como base para a análise aqui desenvolvida.

\footnotetext{
${ }^{5}$ Uma proposta similar para os traços- $\varphi$ vem sendo apresentada por diversos autores. Ver Bèjar $(2003,2008)$ e Harley e Ritter (2002).
} 


\section{Subespecificando caso}

A ideia central de McFadden (2007) é a de que um conjunto (ou conjuntos) de traços binários são meios suficientes para lidar com categorias default, em particular o fenômeno conhecido como caso default. Segundo o autor, a decomposição de categorias morfológicas remonta pelo menos a Hjelmslev e Jakobson. Por exemplo, em vez de haver uma categoria pessoa, haveria uma categoria composta por traços como $[+$ speaker, thearer $]$. Tal aparato é primariamente motivado para explicar sincretismo, fenômeno no qual uma única forma aparece com mais de uma função gramatical.

De acordo com McFadden, há pelo menos dois fatores que motivam uma decomposição de traços para a explicação do sincretismo: (a) a possibilidade de uma descrição simplificada de padrões específicos de sincretismo em línguas específicas; (b) a possibilidade de explicar de forma mais abrangente por que certos tipos de sincretismo na verdade ocorrem e outros, não, intra e interlinguisticamente.

Assim, por exemplo, seguindo-se a decomposição de Bierwisch (1967) abaixo, o fato de o alemão mostrar sincretismo entre nominativo/acusativo, mas não nominativo/dativo seria resolvido adotando-se uma decomposição onde nominativo e acusativo possuem ambos o traço [-oblíquo], mas nominativo e dativo não teriam nenhum traço (ou, melhor dizendo, valor de traço) em comum.

\begin{tabular}{ll}
\hline Caso & Traços \\
\hline Nominativo & [-oblíquo,-regido] \\
Acusativo & [-oblíquo,+regido] \\
Genitive & [+oblique,-regido] \\
Dative & [+oblique,+regido $]$ \\
\hline
\end{tabular}

Quadro 1: casos em alemão de acordo com Bierwisch (1967).

Entretanto, segundo McFadden, nada impede que haja uma decomposição diferente na qual nominativo e dativo sejam de uma mesma categoria. Assim, para restringir que tipos de traços entram na formação de uma categoria morfológica complexa, McFadden (2007, p. 226) propõe a seguinte restrição: 


\section{(11) Restrição Morfológica de Traço}

Cada traço proposto para definir morfologicamente categorias deve ter motivação independente da forma morfológica que descreve.

Em outras palavras, um traço estipulado para definir uma categoria morfológica, como caso, por exemplo, deve ter uma motivação sintática ou semântica ou pragmática, por exemplo. Assim, uma categoria como pessoa pode ser caracterizada semanticamente, com traços como [speaker, hearer], gramaticalizados do discurso. Mas, por outro lado, uma caracterização semântica para dativo ou genitivo parece não ser acessível. Assim, uma decomposição das tradicionais categorias casuais em traços geralmente leva em conta noções vagas, que passeiam pela sintaxe e pela semântica. Um exemplo disso é a motivação proposta por Halle e Vaux:

O especificação de traço [-oblíquo] é atribuída a nominais que sejam argumentos do verbo; [+oblíquo] é atribuído a nominais que não são argumentos do verbo. $\mathrm{O}$ traço [-estrutural] é atribuído a nominais em posição não-estruturais/semânticas; [+estrutural] é atribuído a nominais com base em sua posição na estrutura sintática, exclusivamente. $\mathrm{O}$ traço [-superior] é atribuído a nominais em posição de regência na estrutura sintática; [+superior] é atribuído a nominais em posição de não-regência. [-livre] é atribuído a nominais com um papel consistente na estrutura argumental; [+livre] é atribuído a nominais cujo papel na estrutura argumental varia (HALLE \& VAUX, 1998, p. 5).

Segundo McFadden, o esforço dos autores em caracterizar os traços de caso reflete o fato de que tais traços não podem ser estipulados puramente por categorias morfológicas, mas há pelo menos uma tentativa de relacioná-los aos contextos sintático-semânticos em que aparecem. Assim, o autor adota uma versão mais forte da Restrição Morfológica de Traço:

\section{Restrição Morfológica de Traço (versão final)}

A inclusão de um traço particular para lidar com padrões de formas morfológicas deve ser acompanhada por uma teoria explícita de sua distribuição em termos sintáticos/semânticos (MCFADDEN, 2007, p. 228).

Em outras palavras, se um traço [-oblíquo] for estabelecido para dar conta do sincretismo nominativo/acusativo, por exemplo, deve-se também formular as regras de sua atribuição. Ainda de acordo com o autor, os traços que compõem uma categoria são independentes uns dos outros. Isso pode esclarecer a maneira com que os casos são atribuídos a DPs ao mesmo tempo em que se estabelecem os padrões de sincretismo. 
Segundo McFadden, um dos fenômenos para os quais esse raciocínio é útil é o chamado caso default. Em línguas com um sistema morfológico de caso, há normalmente um caso que opera como default, aparecendo onde nenhum outro pode ser atribuído. Nos contextos de deslocamento à esquerda, por exemplo, é esperado que o DP deslocado compartilhe o caso do elemento com o qual ele é correferente, mas, às vezes, essa concordância falha e um caso default aparece (SCHÜTZE, 2001).
a. Me, I like beans. ${ }^{6}$
Me.ac, eu gosto feijões
"Eu, eu gosto de feijões"
(inglês)
b. Der/ *Dem Hans, mit dem spreche ich nicht mehr.
O.nom $/ *^{*}$ o.dat Hans com ele.dat falo eu não mais
"Hans, eu não falo com ele nunca mais"
(alemão)
c. Strákarnir, við pá hafði aldrei verið talað.
Garotos.os.nom com eles.ac tiveram nunca falado
"Os garotos, nunca se conversou com eles"
(islandês)

Em inglês, a forma acusativa é a que desempenha a função default, aparecendo em posição de tópico, enquanto em alemão e islandês, esse papel é desempenhado pela forma nominativa.

Para se estabelecer uma teoria para o caso default, uma das questões que devem ser levadas em conta é como se prediz qual caso será o default em uma dada língua. O status default, segundo McFadden, é uma característica da categoria caso e não de uma forma específica que o realiza. Por exemplo, em alemão, nominativo seria a categoria default e não a forma $\operatorname{der}$ (o masc.sing.nom), ou ich (eu nom). O autor nota que, ao observar os exemplos em (16), fica claro que em todas as línguas citadas, exceto o inglês, o caso default é o nominativo. Para McFadden, a chave para entender caso default está em reconhecer sua relação com o caso estrutural de uma dada língua. A ideia é que se pode generalizar sobre a aparição do nominativo como o caso estrutural independente e como o default. Assim, McFadden captura a ideia de que Caso default não é o caso que é atribuído quando outros casos falham, mas a real ausência de caso.

\footnotetext{
${ }^{6}$ Exemplos extraídos de McFadden (2007, p. 229).
} 
McFadden (2007, p. 232) afirma, entretanto, que isso não significa, no sentido morfofonológico, que caso default é a ausência de um marcador realizado de caso. Apesar de o nominativo ser não marcado neste sentido, como em muitas línguas onde ele é o defaut, em outras, ele está associado a uma expressão formal realizada. Em vez disso, isso seria uma declaração morfossintática, reservando-se a determinação de cada categoria de caso.

Categorias como "nominativo" não possuem uma realidade substantiva, mas surgem da combinação de traços (binários, segundo o autor) mais primitivos. Assim, o que de fato é atribuído a um DP são esses traços mais primitivos, independentemente. McFadden estabelece também o mecanismo de marcação dos traços: a) se um traço é estritamente binário, há essencialmente apenas uma regra de atribuição para cada um; b) a marcação relativa do valor de um traço é derivada e não estipulada; c) o valor marcado (positivo) é aquele atribuído quando o DP encontra as condições específicas para tal, e o não marcado (negativo), quando isso não se dá.

Dessa maneira, "nominativo" em línguas como o alemão é o nome para a categoria definida quando todos os valores dos traços de caso são não marcados, ou seja, aquela que emerge em DPs cujas regras de atribuição dos traços de caso falham em sua aplicação.

A análise de McFadden é um aprimoramento no que diz respeito ao sincretismo encontrado em alguns casos morfológicos em línguas como o alemão. O autor estende sua análise também a línguas como o inglês, que não possuem caso morfológico além do que é capturado em seu paradigma pronominal. Entretanto, ao apontar a diferença existente entre caso morfológico e Caso abstrato, cuja função está ligada ao licenciamento do DP, o autor não explica como se dá a verificação dos traços que definem tais casos morfológicos. Além disso, a análise não prediz a alternância entre formas estruturais (nominativo e acusativo) e oblíquas (dativo, genitivo), o que acontece, por exemplo, em PB.

\section{Uma hierarquia para caso}

Os pronomes pessoais apresentam comportamento peculiar em PB. Um sincretismo generalizado aparece no paradigma pronominal desta língua: a forma 
nominativa é a forma predominante em todas as pessoas, como pode ser visto no quadro abaixo:

\begin{tabular}{|c|c|c|c|c|c|}
\hline & Nom & Ac & Dat & Dat (Abl) & Gen \\
\hline \multirow[t]{2}{*}{$1 \mathrm{sg}$} & $E u$ & $\mathrm{Me} / \boldsymbol{e u}$ & $\mathrm{Me} / \mathrm{mim} / \mathbf{e u}$ & Comigo/eu & $\operatorname{Meu}[s](\operatorname{minha}[s])$ \\
\hline & & & & & /deu/de mim \\
\hline \multirow[t]{2}{*}{$2 \mathrm{sg}$} & Você/tu & Você/tu/te/lhe & $\boldsymbol{v o c} \hat{e} / \boldsymbol{t u} /$ te/ti/ lhe & Contigo/você & $\operatorname{Seu}[s]($ sua $[s])$ \\
\hline & & & & & $\mid \operatorname{teu}[s](t u a \mid s])$ \\
\hline $3 \mathrm{sg}$ & Ele(ela) & Ele(ela)/se & Ele(ela)/ lhe & Ele(ela) & Dele(dela) \\
\hline \multirow[t]{2}{*}{$1 \mathrm{pl}$} & Nós & Nos/Nós & Nos/nós & Conosco/nós & De nós \\
\hline & /a gente & /a gente & /agente & / a gente & / da gente \\
\hline $2 \mathrm{pl}$ & Vocês & Vocês & Vocês & Vocês & De vocês \\
\hline $3 \mathrm{pl}$ & Eles(elas) & Eles(elas)/se & Eles(elas)/ lhe & Eles(elas) & Deles(delas) \\
\hline
\end{tabular}

Quadro 2: paradigma pronominal em português brasileiro.

No quadro 2, os pronomes em sua forma nominativa são possíveis em quase todas as posições Casuais. Ao mesmo tempo, algumas pessoas pronominais ainda apresentam formas casuais específicas (me, mim, meu, minha, comigo, te, ti, lhe, contigo, conosco, etc.). Outras, entretanto, apesar de mais específicas, podem ocorrer como representantes de mais de um caso (mim, me, lhe), enquanto outras são restritas a determinados casos e não ocorrem senão para representá-los (se, comigo, conosco, meu, sua). Esta hierarquia pode ser explicada a partir da decomposição das funções Casuais desses pronomes. Há duas motivações distintas para uma proposta de decomposição de traços de caso para o sincretismo. Uma é que isso permite uma descrição mais simples dos padrões específicos de sincretismo em línguas específicas. A outra é que isso pode ser potencialmente usado para explicar de forma mais geral por que certos tipos de sincretismos de fato ocorrem e outros não, intra e interlinguisticamente.

Para uma caracterização dos traços componentes para definir que traços de caso são relevantes nesta língua, parto da concepção histórica da herança dos casos latinos no paradigma pronominal do português. Como pode ser observado no quadro 2, existem 
aparentemente cinco casos relevantes para o sistema pronominal em PB: nominativo, acusativo, dativo, ablativo e genitivo. Nominativo e acusativo são os casos tradicionalmente designados ao sujeito e ao objeto direto, respectivamente. Estes casos são estabelecidos nas relações entre o verbo e seus argumentos. Os casos restantes são denominados casos oblíquos, pois não estão diretamente ligados à argumentação verbal. Como será visto mais adiante, os chamados casos estruturais não possuem uma especificação de traços, pois estão intrinsecamente ligados ao licenciamento do DP como defendido por McFadden (2004, 2007) e sua interpretação depende tão somente de onde o DP teve seus traços formais valorados. Já os casos oblíquos possuem traços específicos, pois seu licenciamento não depende de nenhum outro traço formal presente no DP. Assim, uma tipologia dos traços de caso para o PB deve levar em conta somente aqueles que determinam uma especificação do DP pronominal, como os oblíquos.

Assumiremos que traços de caso não possuem conteúdo semântico intrínseco. Como lembra McFadden (2007), os traços formativos de caso devem ser derivados das relações sintático-semânticas de que participam. Então, por exemplo, a estipulação de um traço [OBLÍQUO] deve levar em conta em que condições sintáticas e semânticas ele pode aparecer, mas não de seu conteúdo semântico.

Adoto, assim, a representação em (14) como sendo a representação geométrica de caso em PB, cuja notação está explicitada no Quadro 3:

\section{(14) [C[OBLÍQUO[GENITIVO]]]}

\begin{tabular}{|c|c|}
\hline Traço & Notação \\
\hline$[\mathrm{C}]$ & $\begin{array}{l}\text { Representa a categoria caso. }[\mathrm{C}] \text { é o traço minimamente } \\
\text { distintivo para caso. Um nominal maximamente } \\
\text { subespecificado para caso deve possuir apenas o traço }[u \mathrm{C}] .\end{array}$ \\
\hline [OBLÍQUO] & $\begin{array}{l}\text { A presença de [OBLÍQUO] distingue DPs que podem aparecer } \\
\text { em posição de argumentos do verbo daqueles que são } \\
\text { complementos de um } \mathrm{P} \text { ou de um D. A presença deste traço } \\
\text { determina que o domínio de valoração dos traços de caso do } \\
\text { DP deve ser um PP (oblíquos em geral) ou um DP (genitivo). } \\
\text { Desta forma [OBLÍQUO] pode também ser visto como uma } \\
\text { (sub)categoria distintiva dentro de caso, pois sua presença } \\
\text { restringe o domínio de valoração dos traços de caso. }\end{array}$ \\
\hline
\end{tabular}




\begin{tabular}{|l|l|}
\hline \multirow{2}{*}{ [GENITIVO] } & $\begin{array}{l}\text { Determina que um nominal tem seu domínio de valoração de } \\
\text { traços dentro do DP. Em PB, a presença deste traço identifica } \\
\text { o DP como possessivo, visto que esta é a única possibilidade de } \\
\text { caso que tem o DP como domínio de valoração. }\end{array}$ \\
\hline
\end{tabular}

Quadro 3: notação dos traços de Caso no PB.

Como apontou Telmo Móia ${ }^{7}$, em discussão sobre o quadro 2, o ablativo nada mais seria do que uma especificação lexical da preposição, cujo valor do caso será oblíquo. Desta forma, não haveria "herança" ablativa no quadro pronominal do $\mathrm{PB}$, mas apenas uma especificação de cunho puramente morfológico.

Essa representação de traços para caso permite uma leitura mais simplificada do fenômeno do sincretismo no sistema pronominal em PB: quanto menos especificado para caso for o pronome, mais abrangente é sua distribuição. Assim, assumo com McFadden que a forma nominativa do pronome é a que apresenta uma distribuição quase irrestrita porque é a que representa uma configuração de traços maximamente subespecificada. Portanto, em PB, todas as formas em negrito no quadro 2 podem aparecer representando praticamente qualquer função Casual na sentença, pois sua estrutura de caso é maximamente subespecificada, apresentando apenas o traço [C]. A representação dos outros pronomes em PB de acordo com seus traços de caso vai depender do mecanismo de valoração de seus traços, o que será abordado a seguir.

\section{Condições para valoração dos traços de caso}

Uma teoria de concordância baseada em subespecificação de traços de caso implica adaptações do tradicional conceito de Agree (CHOMSKY, 1999a). Assumo com Chomsky (1999a) que o que ativa a operação Agree são traços não valorados que entram na derivação. Uma vez que pelo menos um traço formal entra na derivação, ele determina que a operação Agree deve ser acionada para que este traço seja valorado. Objetivamente, as condições para match dos traços $\varphi$ são suficientes para que também as condições de valoração dos traços de caso operem. Os elementos que participam do processo de valoração dos traços de caso do DP já estabeleceram match para os traços $\varphi$, não sendo necessária uma segunda avaliação de

\footnotetext{
${ }^{7}$ Discussão que surgiu a partir da apresentação no IV Workshop do projeto Romania Nova, em Campos do Jordão, São Paulo, em 2010.
} 
tais elementos. Segundo Chomsky (1999b, p. 4), "Case itself is not matched, but deleted under matching of $\varphi$-features". Já para os DPs que estabelecerão concordância com elementos que não possuem traços $\varphi$ não valorados, basta que eles possuam pelo menos um traço de caso não valorado para que Agree seja ativado.

Valoração aqui é concebida como a cópia do rótulo que o traço interpretável carrega (BÉJAR, 2003, 2008):

(15) O alvo valora a sonda se traços do alvo acarretar traços da sonda.

Portanto, os traços do alvo devem ser um super-conjunto dos traços da sonda, como $\mathrm{P} \leq \mathrm{G}$. A valoração dos traços de caso se dá simultaneamente a dos traços $\varphi$ e é a leitura do resultado desta valoração conjunta que gera as diferentes formas do pronome em PF. Desta forma, por exemplo, os resultados previstos para a valoração dos traços de caso para os pronomes de $1^{a}$ pessoa do singular possessiva, em PB, são os seguintes:

(16) a. Ela puxou na cabeça deu.

b. Ela puxou na cabeça de mim.

c. Ela puxou na minha cabeça.

\begin{tabular}{lll}
\hline Sonda & Alvo & Spell out \\
\hline & {$[\mathrm{C}]$} & $\mathrm{EU}$ \\
& {$[\mathrm{C}[\mathrm{OBL}]]$} & $\mathrm{EU}$ \\
& {$[\mathrm{C}[\mathrm{OBL}[\mathrm{GEN}]]]$} & $\mathrm{EU}$ \\
& Agree é bem sucedido & \\
\hline$u \mathrm{C}]$ &
\end{tabular}

Tabela 1: Agree dos traços de caso com pares sonda-alvo (16a).

\begin{tabular}{lll}
\hline Sonda & Alvo & Spell out \\
\hline & {$[\mathrm{C}[\mathrm{OBL}]]$} & MIM \\
& {$[\mathrm{C}[\mathrm{OBL}[\mathrm{GEN}]]]$} & $\mathrm{OK}$ \\
{$[u \mathrm{C}[\mathrm{OBL}]]$} & Agree é bem sucedido & \\
\hline
\end{tabular}

Tabela 2: Agree dos traços de caso com pares sonda-alvo (16b). 


\begin{tabular}{lll}
\hline Sonda & Alvo & Spell out \\
\hline & {$[\mathrm{C}[\mathrm{OBL}[\mathrm{GEN}]]]$} & MEU/MINHA \\
{$[\varkappa \mathrm{C}[\mathrm{OBL}[\mathrm{GEN}]]]$} & Agree é bem sucedido & \\
\hline
\end{tabular}

Tabela 3: Agree dos traços de caso com pares sonda-alvo (16c).

Assim, como mencionado acima, a forma nominativa é aquela que menos traços de caso possui em sua composição. Desta forma, similarmente ao alemão, as formas nominativas em $\mathrm{PB}$ são as maximamente subespecificadas (ou categorias default, na terminologia de $\mathrm{McF}$ adden), pois apresentam apenas o traço $[u \mathrm{C}]$, não interpretável, em sua estrutura e, assim, podem assumir qualquer posição na sentença, pois os alvos potenciais para caso terão no mínimo a mesma especificação. Por exemplo, um DP especificado apenas com o traço $[u C]$ e que valore este traço em T, só encontrará um traço $[\mathrm{C}]$ e, portanto, resultará numa forma nominativa sempre. Já um DP especificado com os traços $[u \mathrm{C}[\mathrm{OBL}]]$, mesmo que, ignorando-se os meios para tal, termine por alcançar $\mathrm{T}$ para ter seu traço valorado, terá como resultado a forma nominativa do pronome, pois apenas os traços que são identificados e valorados estão disponíveis para PF.

Portanto, a realização de um DP em sua forma "nominativa" será determinada pela valoração do traço de caso deste DP em um T, cuja especificação para caso será sempre [C]. Para o contexto "acusativo", o processo de valoração de traços é idêntico. Um aparente problema surge para o contexto acusativo, pois esta configuração pode gerar dois outputs: um clítico (me) e outro não clítico (eu). Isto é resolvido se adotarmos, juntamente Déchaine e Wiltchko (2002) que clíticos não possuem a camada D, na terminologia das autoras. Assim, a ausência do traço [D], num contexto acusativo, geraria um elemento clítico, enquanto sua presença seria responsável por um elemento pronominal pleno. Portanto, não há distinção entre formas Casuais "estruturais". Há apenas uma distinção entre elementos clíticos e não clíticos

A realização dos casos oblíquos, os "inerentes" na terminologia tradicional, é um pouco mais exigente. No que tange aos traços $\varphi$ do DP que entra em uma configuração oblíqua, Agree para tais traços não opera uma vez que não há traços não interpretáveis desse tipo. Apenas traços de caso são sondados para ativar concordância. Assim, os alvos potenciais dos traços não valorados de caso do DP são P e D. P e D serão sempre mais 
especificados para caso que outros núcleos funcionais. P e D são alvos potenciais para qualquer DP especificado com pelo menos o traço [OBLÍQUO] não valorado. Qualquer DP pronominal que tenha seus traços de caso valorados por P deverá ter pelo menos a mesma especificação de traços de $\mathrm{P}$ para que a valoração de seus traços ocorra. A valoração dos traços de caso deve operar pela interseção dos traços do alvo pela sonda.

O DP que tem seu(s) traço(s) de caso valorado(s) em D será interpretado como genitivo, independentemente de sua realização. De acordo com Abney (1987), a estrutura do DP é semelhante à da sentença. DET é o locus de concordância no domínio do DP. Magalhães (2004) propõe que o processo de concordância dentro do DP é equivalente ao da sentença também nos moldes de Agree. Assumo que a valoração de caso proposta para o nível da sentença opera no domínio do DP. E sendo POSS o responsável pelo licenciamento do possessivo, é ele que valora [GENITIVO] no nominal.

A realização do possessivo vai depender de sua estrutura interna, como defendido aqui. Desta maneira, como DPs não-pronominais em PB não possuem uma forma Casual específica para diferentes casos, ou seja, não há uma especificação do nominal não pronominal para a forma possessiva (nem mesmo uma morfologia própria indicativa, como o que ocorre no inglês), sua realização será indicada como possessiva pela inserção de um elemento dummy, a preposição de. Isto é o que ocorre mesmo em línguas que possuem uma forma específica para o genitivo, como o inglês. Apesar de nesta língua haver um morfema específico para as relações de posse ('S), a preposição of (de) pode desempenhar este papel.

(17) a. John's car

John.gen carro

b.The car of John

O carro de John

Com os pronomes, a realização da forma genitiva segue a mesma tendência: as formas mais especificadas são estruturalmente mais exigentes. A realização de my (men/minha) depende da especificação do conjunto de caso do DP pronominal. Se este pronome é especificado para os traços [uC[OBL[GEN]]], então ele gerará a forma $m y$, pois todos os traços são codificados (e valorados) pelo alvo. Mas, se o pronome for subespecificado para qualquer traço da árvore de caso, outra forma, menos específica, aparecerá. O mesmo ocorre com o PB. Nesta língua, o possessivo pronominal segue uma hierarquia que pode ser vista nas tabelas 1,2 e 3 . 
Todas as formas pronominais em (17) têm a mesma leitura possessiva e possuem a mesma especificação de traços $\varphi$. Como dito anteriormente, os traços de caso não interferem na interpretação desses elementos em LF, sendo este um recurso morfossintático. São os traços de caso, juntamente com os traços $\varphi$, que definem as diferentes formas e posições dos elementos na sentença. Portanto, as diferentes formas em (18) são o resultado da especificação dos diferentes traços de caso possíveis em PB para a primeira pessoa do singular, como ilustrado abaixo:
a. Ela puxou na cabeça deu $\equiv[\mathrm{C}]$.
b. Ela puxou na cabeça de mim $\equiv[\mathrm{C}[\mathrm{OBL}]]$.
c. Ela puxou na minha $\equiv[\mathrm{C}[\mathrm{OBL}[\mathrm{GEN}]]]$ cabeça.

A valoração dos traços em cada uma das sentenças vai seguir o mesmo mecanismo já estipulado acima, mas a diferença residirá em quais traços à sonda terá valorado. $\mathrm{O}$ resultado da operação de valoração desses traços é a realização de formas mais subespecificadas na medida que menos traços na sonda são valorados. Ou seja, quanto mais traços valorados na sonda, mais específica será a forma.

\section{Referências}

ABNEY, S. The English noun phrase in its sentential aspect. Tese (Doutorado). Massachusetts: MIT, 1987.

ALBUQUERQUE, E. C. M. M. A variação entre os pronomes eu/mim na posição de complemento verbal na fala em Alagoas: uma analise Sociolingüísta Variacionista. Dissertação (Mestrado em Linguística). Maceió: Universidade Federal de Alagoas, 2006.

BÉJAR, S. Phi-syntax: a theory of agreement. Tese (Doutorado). Toronto: University of Toronto, 2003.

Conditions on Phi-Agree. In: HARBOUR, Daniel et al. (Org.). Phi-Theory: PhiFeatures across modules and interfaces. New York: Oxford University Press, 2008.

BIERWISCH, M. Some semantic universals of German adjectival. Foundations of Language, v. 3, 1967, p. 1-36.

BOECKX, C. Bare syntax. Oxford: Oxford University Press, 2008. Elementary syntactic structures. Cambridge: Cambridge University Press, 2014. 
CHOMSKY, N. Lectures on government and binding. Dordrecht: Foris, 1981.

Minimalist Inquiries: the Framework. MIT Occasional Papers in Linguistics 15. Cambridge, MA: MIT Working Papers in Linguistics, 1998.

Derivation by phase. MIT Occasional Papers in Linguistics 18. Cambridge, MA: MIT Working Papers in Linguistics, 1999a. 1999b.

O programa minimalista. Trad. Eduardo Paiva Raposo. Lisboa: Caminho,

DÉCHAINE, R-M.; WITSCHKO, M. Decomposing pronouns. Linguistic Inquiry, v. 33, n. 3, 2002, p. 409-442.

HALLE, M.; VAUX, B. Theoretical aspects of Indo-European nominal morphology: the nominal declensions of Latin and Armenian. In: JASANOFF, J. et al. (Org.). Mír Curad: Studies in Honor of Calvert Watkins. Innsbruck: Innsbrucker Beiträge zur Sprachwissenschaft, 1998, p. 223-240.

HARLEY, H.; RITTER, E. Person and number in pronouns: a feature-geometric analysis. Language, v. 78, 2002, p. 482-526.

McFADDEN, T. Adventures in resolving redundancy: Case vs. EPP. In: Proceedings of the $26^{\text {th }}$ Penn Linguistics Colloquium, University of Pennsylvania, 2002.

The position of morphological case in the derivation: a study on the syntaxmorphology interface. PhD Dissertation, University of Pennsylvania, 2004.

Default case and the status of compound categories in Distributed Morphology. Manuscrito não publicado, 2007.

MAGALHÃES, T. M. V. A valoração dos traços de concordância dentro do DP. D.E.L.T.A., v. 20, no 1, 2004, p. 149-170.

NICHOLS, Johanna. Linguistic diversity in space and time. Londres; Chicago: University of Chicago Press, 1992.

ROUVERET, A.; VERGNAUD, Jean-Roger. Specifying reference to the subject. French causatives and conditions on representations. Linguistic Inquiry, v. 11, 1980, p. 97-202.

SCHÜTZE, C. On the nature of default case. Syntax, v. 4, 2001, p. 205-238.

SIGURĐSSON, H. A. The locus of case and agreement. Working Papers in Scandinavian Syntax, v. 65, 2000, p. 65-108.

Case: abstract vs. morphological. In: BRANDNER, E.; ZINSMEISTER, H.

(Org.). New perspectives on Case theory. Stanford: CSLI Publications, 2003, p. 223268. 


\section{Abstract}

This paper presents a mechanism to deal with the realization of the same pronominal form in different syntactic contexts. Data are presented comparatively in order to demonstrate the idea that case is a determining category in pronominal distribution. It demonstrates how a traditional case theory is insufficient to deal with such phenomenon. A decomposition of the case categories is suggested as the optimal solution for case configuration, taking into account evidence from languages such as English and Brazilian Portuguese, which show case difference only in their personal pronouns. Case, then, is treated from a feature bierarchy, following Harley and Ritter (2002). Thus, case categories for Brazilian Portuguese obey $[C[O B L[G E N]]]$. A value mechanism for those features is proposed and the different pronominal outputs are the result of such mechanism, which explains the actual pronominal paradigm in Portuguese.

Keywords: Default case. Syncretism. Pronouns. Brazilian Portuguese. 